\title{
BMJ Open What work is required to implement and sustain the National Surgical Quality Improvement Program (NSQIP)? A qualitative study of NSQIP implementation in Alberta, Canada
}

\author{
Dawn Schroeder, ${ }^{1}$ Thea Luig, ${ }^{1}$ Sanjay Beesoon, ${ }^{2}$ Jill Robert, ${ }^{2,3}$ \\ Denise Campbell-Scherer (ID) ,,5 Mary Brindle ${ }^{2,6}$
}

To cite: Schroeder D, Luig T, Beesoon S, et al. What work is required to implement and sustain the National Surgical Quality Improvement Program (NSQIP)? A qualitative study of NSQIP implementation in Alberta, Canada. BMJ Open 2021;11:e044720. doi:10.1136/ bmjopen-2020-044720

- Prepublication history and additional supplemental material for this paper are available online. To view these files, please visit the journal online (http://dx.doi.org/10.1136/ bmjopen-2020-044720).

Received 14 September 2020 Accepted 15 September 2021

D Check for updates

(c) Author(s) (or their employer(s)) 2021. Re-use permitted under CC BY-NC. No commercial re-use. See rights and permissions. Published by BMJ.

For numbered affiliations see end of article.

\section{Correspondence to} Denise Campbell-Scherer; denise.campbell-scherer@ ualberta.ca

\section{ABSTRACT}

Objectives Hospitals introducing the National Surgical Quality Improvement Program (NSQIP) face implementation challenges. To understand the work of embedding NSQIP into routine practice, we explored interactions between contextual factors and the work among implementation teams at the individual, team and organisational level to illuminate how to support and sustain NSQIP implementation.

Design Qualitative interpretative study using thematic analysis.

Setting Five contextually diverse hospital sites in Alberta, Canada, for in-depth interviewing and four additional hospitals for observation of NSQIP meetings.

Participants 9 Surgeon and Anaesthesiologist Champions; 6 Surgical Clinical Reviewers; 4 Directors and 1 Surgical Site Manager; 3 Operating Room Managers; 3 Quality Improvement Consultants; 1 Surgeon and 1 Provincial NSQIP Lead.

Methods To capture context, process and the dynamic interplay between the two, we integrated the Consolidated Framework for Implementation Research (CFIR) and Normalisation Process Theory (NPT) to guide data collection and analysis. 28 individual semi-structured interviews with key informants and observations with field notes of 10 NSQIP meetings were conducted. Data were coded deductively and inductively and analysed thematically.

Results Key findings informed by CFIR describe the impact of Provincial Collaboratives, leadership support and resources to support NSQIP work. Key findings illuminated by NPT highlight how teams overcame mistrust in NSQIP through relationship building, creating formative spaces to inform collective understandings of NSQIP and inviting feedback from professional groups to cocreate quality improvement solutions. This approach led to increased engagement with NSQIP data and encouraged shifts in conversations within and between nursing and physician groups from problems to solutions based.

Conclusions The work the teams did to implement and sustain NSQIP highlights the need for time and resources to develop shared understandings of work processes, reorganise themselves to work together and understand how to help others in the surgical community interpret and value using NSQIP to improve care.

\section{Strengths and limitations of this study}

- This is one of the largest studies of the implementation experience of the National Surgical Quality Improvement Program (NSQIP) to date; it provides a rich understanding of these experiences from the perspectives of multiple healthcare professional roles.

- The integration of the Consolidated Framework for Implementation Research and Normalisation Process Theory illuminated interactions between conditions and the work needed for different clinical settings to embed NSQIP and support quality improvement initiatives.

- The partnership between Alberta Health Services' Surgery Strategic Clinical Network and Physician Learning Program researchers at the University of Alberta provided connections to operational and methodological expertise to address project needs and its application.

- Due to participants' demanding work schedules, we were limited to one interview per participant and a cross-sectional design.

\section{INTRODUCTION}

Evolving a new way of working together as surgical teams requires change that goes beyond adopting different procedures, rules and structures to support quality improvement (QI). What is transformative is an understanding of the cognitive and social dimensions of change: how do people make sense of new procedures, how do they work to put them in place, how do people re-envision rules and structures together to evolve new ways of working? A significant enabler of improvement is the American College of Surgeons' National Surgical Quality Improvement Program (NSQIP). ${ }^{1}$ NSQIP is an effective tool to track and measure risk-adjusted outcomes to inform decisions to improve 
surgical care ${ }^{1-5}$ and reduce costs. ${ }^{6-9}$ Since the 1990 s, continuous tracking of 30-day morbidity and mortality outcomes provided by NSQIP data helped surgeons, surgical team members and health administration focus in on areas such as high surgical site infection rates, or catheter-associated infections, to address care gaps through QI initiatives. As evidence-based interventions are implemented to address these gaps, the effects of these interventions can be observed in the ongoing NSQIP data. ${ }^{4}$ However, NSQIP is a tool; only as effective as the degree to which it is integrated into a new collaborative work-flow. A few studies illuminate factors to drive QI such as frequency of NSQIP team member meetings, leadership support and membership in surgical quality collaboratives. Obstacles to embedding NSQIP relate to scepticism and resistance among some surgeons to the validity and reporting of data. ${ }^{10-12}$ What is not understood are the cognitive and social processes teams individually and collectively engage in to make sense of NSQIP and complete the work to integrate the programme into existing work-flows.

To explore this, we drew on the Consolidated Framework for Implementation Research (CFIR) ${ }^{13}$ and Normalisation Process Theory (NPT) ${ }^{14}$ to study the 2018 rollout of NSQIP to nine hospital sites in Alberta, Canada. CFIR provides a scaffolding of instrumental factors to situate and enable implementation work. ${ }^{13}$ NPT describes processes that reveal how people make sense of and enact the work to embed innovations into routine practice. ${ }^{14}$ Integrating both theoretical perspectives, we explored the work of embedding NSQIP into routine surgical practice, and the contextual factors that enable this work. The objective of this qualitative study was to explore and describe the cognitive work, social processes and contextual factors that influenced NSQIP implementation and sustainability at the individual, implementation team and site levels across the nine expansion hospital sites.

\section{Adoption of NSQIP in Alberta, Canada}

Prior to NSQIP Alberta Health Services (AHS) (the provincial health services delivery system) used several data reporting systems to track surgical data. However, access to comprehensive reports for different surgical specialties varied. Local QI initiatives prior to NSQIP were largely driven by individuals with academic interest rather than from a health systems perspective that would facilitate continuous tracking and feedback loops to support systematic improvements in care. The decision to adopt NSQIP followed requests from surgeons and departments of surgery leadership for comprehensive data in all surgical specialties. AHS decided to adopt NSQIP at high volume surgical centres and piloted the programme in five hospitals in 2015. Following a positive economic evaluation of the pilot, in 2018, AHS expanded NSQIP to an additional nine hospital sites. ${ }^{8}$

For both the 2015 pilot and the 2018 expansion rollout, AHS' Surgery Strategic Clinical Network (Surgery SCN) facilitated and supported the implementation of NSQIP in high volume surgical sites. The Surgery SCN is a provincial network of clinicians, leadership and researchers, who are committed to improving surgical quality of care. To participate in NSQIP, AHS pays the American College of Surgeons an annual fee for each NSQIP participating hospital to cover costs associated with training and support for a Surgical Clinical Reviewer (SCR), surgical data analysis and the production of various surgical data reports to help target areas for QI efforts. At a minimum, each NSQIP participating site must enrol a Surgeon Champion to facilitate the implementation of NSQIP and an SCR to collect and submit surgical data to the NSQIP database. ${ }^{15}$ In Alberta, the Surgery SCN facilitated the enrolment of implementation teams for each site. The teams consisted of one surgeon and one anaesthesiologist to act as physician champions, one Executive Director/ Director/Manager of surgical services (to protect anonymity, the term 'Director' is used for all three roles) and one or two SCRs, depending on the site's surgical volume. In 2019, members of the Surgery SCN (MB, JR and SB) approached the Physician Learning Program (PLP) research team (DC-S, TL and DS) to study barriers and facilitators for NSQIP implementation at the nine expansion sites and make appropriate recommendations.

\section{METHODS}

We used a qualitative design to study the 2018 NSQIP implementation in the nine expansion hospital sites across Alberta. The design of this study from conception to analysis and the writing of the manuscript was a collaborative effort between members of the AHS Surgery SCN and PLP researchers. Our multidisciplinary team included clinicians, clinical researchers and an epidemiologist contributing deep contextual knowledge to project design, feasibility, recruitment and analysis; and a qualitative researcher, an anthropologist and a clinician contributing background in implementation science and methodological expertise. None of the PLP researchers had a prior relationship with any of the study participants or study sites. This research followed the Standard for Reporting Qualitative Research (online supplemental appendix 1). ${ }^{16}$

\section{Site selection, recruitment and data collection}

Out of nine expansion hospital sites, we selected five contextually different hospitals for in-depth interviews based on the following criteria: academic (one from each of the two population centres), non-academic, rural and community-based. The remaining four hospitals were included for observations of NSQIP meetings. This study was approved by the Health Research Ethics Board of the University of Alberta (Pro00088327) and received operations approval from AHS. All research participants provided informed consent.

Data collection and analysis drew on the $\mathrm{CFIR}^{13}$ and NPT. ${ }^{14}$ CFIR synthesises 19 theories into a list of constructs, which identify factors that may influence 
Table 1 Participant characteristics

NSQIP implementation team roles

\begin{tabular}{|c|c|}
\hline Physician Champion & $\mathrm{n}=9$ \\
\hline Surgical Clinical Reviewer (SCR) & $\mathrm{n}=6$ \\
\hline $\begin{array}{l}\text { Executive Director/Director/Manager for Surgical } \\
\text { Services* }\end{array}$ & $\mathrm{n}=5$ \\
\hline \multicolumn{2}{|l|}{ Participant Roles Outside of the Implementation Team } \\
\hline Surgeon Site Lead & $n=1$ \\
\hline Operating Room (OR) Manager & $n=3$ \\
\hline Quality Improvement (QI) Consultant & $n=3$ \\
\hline Provincial NSQIP Lead & $n=1$ \\
\hline
\end{tabular}

*To protect anonymity, the title: 'Director' is used throughout the article in place of the Executive Director/Director/Manager for Surgical Services participant role.

NSQIP, National Surgical Quality Improvement Program.

implementation. ${ }^{13}$ In addition to factors, we needed to understand how people worked to integrate NSQIP. NPT explains the work people do to make sense of and routinise innovations. Overlaying NPT onto CFIR allowed us to study the cognitive work and social processes involved in ensuring that NSQIP is routinised to improve patient outcomes. ${ }^{13} 14$ Based on CFIR and NPT, we developed a semi-structured interview guide and refined it with key informants (online supplemental appendix 2). We used purposive sampling to recruit implementation team members and snowball sampling through referrals from participants to gain insights from diverse perspectives (table 1). Twenty-eight participants consented including 20 out of a total of 21 implementation team members and 8 individuals outside of the implementation teams. One researcher (DS) conducted and audio-recorded all interviews which were transcribed verbatim. At the four observation sites, field notes were collected for 10 NSQIP meetings. We used NVIVO V.12 (QRS International (Americas)) to manage the data.

Three researchers (DS, DC-S and TL) coded six transcripts inductively and deductively using CFIR and NPT. The results were discussed to achieve consensus on the codes to create the coding manual (online supplemental appendix 3). We performed a thematic analysis comparing data within and between codes and crystallised patterns into themes. ${ }^{17}$ The PLP research (DS, DC-S and TL) and Surgery SCN (MB, SB and JR) team met regularly to discuss themes and reflect on the findings. Themes were confirmed through the perspectives of different health professionals within the data. ${ }^{18}$

\section{Patient and public involvement}

Members of the AHS Surgery SCN collaborated with PLP researchers on the design, recruitment, analysis and manuscript writing for this study. No patients were involved in the study.

\section{RESULTS}

The integration of NPT and CFIR revealed vital cognitive and social processes-or using NPT terminology 'work'and contextual conditions enabling the work. Contextual conditions highlighted by CFIR include policies, procedures and operational needs; culture, networks, communications and technical implementation strategies such as governance, meetings and formal training. ${ }^{13}$ Four key NPT informed questions guided our inquiry and structure the findings: (1) What is the work? (2) Who does the work? (3) How was the work done? and (4) How is the work sustained? ${ }^{14}$ Structuring the findings within these questions provides insights into the work at the individual, implementation team and site levels to understand dynamic interplays between cognitive work, social processes and contextual factors that supported and/or acted as barriers to NSQIP implementation.

\section{What is the work?}

NSQIP implementation team members were the Physician Champions, Director and the SCR(s) for each site. Integration of NSQIP required team members to evolve a shared understanding of the operational and technical elements of the intervention and codevelop site-specific implementation processes. Equally crucial, was the work of supporting each other and the broader surgical team in sense-making around who does what, when, with whom and how to integrate NSQIP into their work.

Directors were oriented to NSQIP by the Surgery SCN before hiring the SCR and appointing Physician Champions. The novel SCR role involved both data abstraction through collecting surgical chart data and submitting the data to the NSQIP database, and supporting NSQIP driven QI work. Although AHS supported online QI courses and mandatory training modules through the American College of Surgeons to gain access to the data platform, it was not enough to help SCRs understand what was involved to do the work. The SCRs found-'when you do the training online...seems very straight forward... when you get to the hands-on piece and it's a whole new world' (SCR\#617). Vital support for SCRs understanding of their work included in-person training between experienced SCRs and new SCRs; support from physician champions with data coding challenges and ongoing monthly conference calls between the Provincial NSQIP Lead and SCRs across the province. These supports helped build a community of practice around NSQIP to share experiences and learn from each other.

For many physician champions, NSQIP was an opportunity to access 'objective data as opposed to presenting a, 'I feel or I think or I see' to engage others with QI changes' (Physician Champion\#497). Their understanding about NSQIP came from monthly conference calls with the Provincial NSQIP Lead and experienced physician champions, and readings. These calls supported understandings of NSQIP generated reports, expectations for implementation within the first year and ways to implement and sustain QI projects. However, as understandings 
of NSQIP deepened, one physician champion's initial excitement changed to disappointment as they questioned the robustness of sampling techniques and the poor fit between subvariables they could collect data on and data they wanted at their community-based site. What was first perceived as a 'powerful tool' became a 'very vanilla bland look at some variables' (Physician Champion\#816). While most Physician Champions were excited about NSQIP data and found it useful to inform QI initiatives, there were times when scheduling and resource constraints made it difficult for some Champions to attend monthly conference calls or do NSQIP work. Resource constraints at some of the communitybased hospital sites included: not having a work laptop or designated workspace to watch monthly conference presentations or work on NSQIP activities. At sites where these constraints were present, the potential for loss of interest may jeopardise NSQIP implementation efforts.

As the NSQIP teams were developing a shared understanding of roles and processes, they engaged with surgical teams to support sense-making and noted reactions to NSQIP. Initially, nursing groups perceived NSQIP positively, whereas physician reactions ranged from excitement and curiosity, to indifference and resistance. More than 6 months into implementation, one site found some physicians were doing some of the QI recommendations coming from the data such as 'putting on expensive dressings' but 'were still a little sceptical' of NSQIP (Physician Champion\#922). Knowing that some physicians were still sceptical of the programme led to an open forum where physicians raised concerns, such as 'data being left out and missing the curve, you know your numbers are showing you're not doing a good job' or 'how this data is going to be used, who's going to see it' (Physician Champion\#922). Understanding these concerns was essential to inform ongoing open dialogues between implementation team members and physicians to help physicians see the value and purpose of NSQIP. Additional representative quotes are highlighted in box 1 .

\section{Who does the work?}

As implementation teams engaged with surgical teams, leadership and/or QI professionals to create awareness about NSQIP and support QI work driven by NSQIP data, ambiguity around the role of the SCR in QI initiatives surfaced. For example, as the SCR role evolved from purely data abstraction to include QI work, many questioned whether they would support or lead QI. For some, this question resulted in 'blurred lines' between the SCR and existing QI Consultant roles for NSQIP driven QI work (SCR \#548). At one site, the Director and QI Consultant recognised value in developing a work relationship between the SCR and QI Consultant early on to understand how their roles inform and complement each other. This relationship led to the early enrolment of the QI Consultant onto the NSQIP leadership team and evolved into a strong collaborative relationship between the SCR and QI Consultant on QI projects.

\section{Box 1 Representative quotes}

\section{What was the work?}

SCR\#320: 'So we were able to get quick contact with the SCRs...over on the pilot site hospital, and just to see how they do things, how they organize their days, what their priorities are, how they balance work demands and kind of how they saw their program roll out'

SCR\#548: 'And provincially, the NSQIP lead, who's kind of our connection between our site programs and the S.C.N., he's very available, especially with technology as well. And he actually has come down to do a few site visits as well so, I feel like that's definitely, definitely been an open door. And tries I think to, I think, support us as best he can' SCR\#320: 'we try to get together... even informally—as SCRs, just to find out how things are going, how we're managing things, what are tips and tricks we've learnt, and also to have a little bit of a social aspect too, because I think you learn ... you build those relationships in and outside of work' 'SCR\#548: But as a provincial group with the S.C.R.s-and that's been a good opportunity to just ask questions to see if others have had that experience and... as well you can ask clinical support with NSQIP and they'll get back to you if there's something you're really struggling with. So, I have utilized that as well. And then over time just got more comfortable with that' Physician Champion\#215: 'So it's like a group learning. . . Like I keep asking them-What did you do at the (Pilot Hospital Name) to get from point A to point B? It's always good to share. We don't want to reinvent the wheel' Physician Champion\#293: 'Most of these meetings are on Skype for Business, and I don't have access to that. .. in my hospital doctors don't have computers. We don't have a workstation... So I have nowhere where I could even sit down and follow this meeting'

Physician Champion\#937:'we get very little criticism when l'm presenting at the surgical site. And we get very little push-back, and even when we said 'Oh, we have too high of an infection rate... We got answers immediately... That's unheard of. Like usually, you get dead silence, right?'

Physician Champion\#497: 'a bit of a mixed bag... some people are concerned there's going to be sort of a punitive aspect to it. like a public shaming...some people are excited. Some people see an opportunity to leverage the program into improving things...some people are more, take a more, you got to prove it to me kind of attitude'

Director\#471: 'surgical suite advisory committee meeting where (SCR name) came and presented some of the data she had collected, what the goals of the program were. And we had physicians completely disengaged from that process and visibly so in that meeting'

ORMGR (\#652): 'I think even like spy on them were some of the terms that were actually used. They felt like...the man was trying to watch what they were doing and then judge and change their practices'

\section{Who does the work?}

SCR\#548: 'I've had minimal with the Q.I. consultant and to be honest, that's one area l've struggled with because just kind of because some Q.I. is supposed to be part of my role, it's been I've had a...I guess a bit of uncertainty on what that relationship is supposed to look like... So, we are starting to get more collaboration there, which has been good' QI Consultant\#332: 'she's looked at her data (referring to the SCR).. and then we've kind of looked at it together....and then l've basically just helped her dig a little deeper into the data'

Director\#163: 'I participate in the surgeon meetings, add input into kind of priority setting with her (referring to the SCR)... Kind of help influence some of those initiatives in the other units, for her, when she gets pushback from leadership around that'

Director\#482: 'My role has more been as a coach just to say we need to keep moving and what obstacles do you have, what can I do to help you, let's do this' 


\section{Box 1 Continued}

SCR\#617: 'my executive director...very helpful and just trying to help me understand first of all, being in the admin world was a new world. So, really just helping me learn like which meetings, yes, I was required to attend or how to represent you know, the team or she would review presentations for me. I would prepare them, send them out, she would review them. And she was also just there as like a good support when I would be presenting NSQIP to whether it would be physicians or different groups'

PC(\#120): 'to do the site (leadership role name) and the champion, worked out quite nicely... probably the best unifying quality initiative we could have, that gave us an opportunity to look at all areas in terms of where surgery and peri-operative care works... it meant for some extra meetings for sure... but for me it worked out well'

OR Manager\#749: 'it's a lot more work for sure and...the SCR is just so gung-ho to do all, like everything now. And I think it's my job to balance that a little bit with reality of, okay we have, we still have to provide care, we can't, we have to look at the change management theory and processes. You can't do everything all at once, so, you know, kind of taking a step back and bringing that into a more like timeline perspective' QI Consultant\#649: '[(SCR Name]) and I've collaborated a lot on projects. She kind of gives me updates in terms of what's happening. She keeps me in the know, what the data is saying, then we work together. Then I can let her know what other projects we're working on, because of course I do quality more broadly. She's very specific, for NSQIP. But then I'm able to kind of keep her in the know in terms of what other projects we're working on that might impact on her work... So I think [(SCR Name]) and I have built a really good relationship

Integration of the new SCR role into existing groups benefited from Physician Champion and Director supports. For example, providing feedback on presentations, attending to any push-back towards SCRs, and providing insights on worries or concerns among surgeons helped the SCRs in their work to prepare presentations and help others value NSQIP. Early introductions also helped SCRs and other groups understand 'the different work that we do, and how we may complement each other, and how we could work together' (SCR\#222). For several Physician Champions, augmenting their Chiefs of Surgery or Anaesthesiology roles to lead NSQIP implementation seemed logical since they established trust in their existing roles.

At some of the sites, the enrolling of Operating Room (OR) Managers, Educators and/or QI Consultants as allies/members of the NSQIP leadership team expanded the team's understanding of contextual resources that may facilitate or hinder QI efforts. An OR Manager who was a member of the NSQIP leadership team found their QI experience and knowledge of the OR environment helped the team prioritise and choose feasible QI projects. Additional representative quotes are highlighted in box 1 .

\section{How was the work done?}

Creating space and time for implementation team members to develop shared understandings was crucial for uptake and integration of NSQIP into surgical facility work. Beyond regular NSQIP team meetings, flexibility was key to create informal spaces where team members could strengthen relationships, experiment with ideas about NSQIP work and address challenges. The busy schedules of the Physician Champions sometimes necessitated NSQIP discussions in-between surgeries. While several SCRs found 'dropping by somebody's office, going for coffee' (SCR\#320), 'text messaging' (SCR\#617) or 'popping up to the O.R. between cases' (SCR\#548) increased contact with Physician Champions to keep each other informed.

Overcoming mistrust among physicians outside of the implementation teams involved thoughtfulness about the interpretation and sharing of data. Recognising mistrust among some physicians related to validity and data use, several NSQIP teams presented data as an aggregate surgical specialty and used supportive language to prevent and/or alleviate fears of 'feeling targeted' (Director\#471). One Physician Champion (\#497) was mindful during a presentation to physicians of 'not pointing the finger at any particular individual...group...or...practise' and using words such as 'we' or 'institution' to instil the point of using NSQIP is to 'get better at what we do'.

Teams also reviewed the data for anomalies to confirm problems they saw in the reports. To distinguish and value NSQIP as a powerful data-driven QI tool, several NSQIP team participants started to remove duplicate data collected by other programmes to increase room to 'data gather on certain areas...we know are meaningful' (Physician Champion\#120). Particular success was realised when teams engaged the surgical facility and leadership broadly in the sense-making process, inviting formative feedback on the data and/or potential solutions at multiple levels. At one site, open dialogues occurred between the NSQIP Leadership team and multiple groups including: Surgical Services, QI Council, OR team and other departments involved with surgical patients.

Overcoming time and resource constraints was pivotal given that the work of the SCRs expanded from data abstraction to include QI work. At a community-based site with limited resources, the Director (\#502) had trouble seeing how QI projects could move forward-'I could just see us talking about it for a very long time and maybe you know, because I'll push to get the one initiative, we'll work on "remove the tube" (a catheter removing strategy). At this site, not having enough people trained in QI to oversee and help implement NSQIP-driven QI changes was a major resource deficiency. Additionally, all of the SCRs expressed concerns over lack of time to juggle their evolving role of leading QI work in addition to data abstraction. At one large urban academic site where there were two SCRs due to the high volume of surgeries, they freed up time for QI by enlisting employees on modified duties to help with the 30-day postdischarge telephone calls. At many sites, the SCRs used 'vacation cycles'-an 8-day cycle with no data abstraction-to dedicate time for QI work. Among Physician Champions, having time to work on NSQIP varied. Negotiating on-call duties allowed one Champion to meet 
weekly with an SCR to work on presentations and review data and research to support QI. Whereas another Champion (\#293) with little time for NSQIP work relied heavily on the SCR for much of the 'legwork'. Additional representative quotes are highlighted in box 2 .

\section{How is the work sustained?}

Changes in how healthcare professionals related to each other is perhaps the most striking aspect of this implementation study. Prior to NSQIP, one Physician Champion (\#120) found physicians 'rarely' came together to talk about QI unless it was a 'real hot button issue'. Conversations often focused on 'peoples' disgruntled relationships with each other'. NSQIP data 'opened up the discussion' on QI between physician groups and between physicians and nurses more constructively. For example, a Director (\#163) perceived a shift in language in the OR from 'problems' to 'more quality focused' as they recalled hearing about a nurse ask a surgeon: 'Well, what about this antibiotic coated suture?... and he's like Oh, okay, I've never thought about it'. As this quote illustrates, participants observed a change in how working with the data moved physicians and nurses to work more collaboratively on QI ideas.

How did this shift in relationships and engagement with QI happen? Several participants found the availability of continuously tracked NSQIP data and evidence-based directions for QI changes resulted in more engagement from healthcare professionals than prior anecdotal reporting. However, availability of data reports and best practice guidelines was not enough to engage broader teams with QI collaborations. At several sites, success among the teams in helping others see value in NSQIP appears to come from a willingness to listen and respond to the concerns of others while using deliberate messaging that supports QI as an institutional problem to solve rather than an individual problem with potential punitive repercussions. What triggered productive conversations about QI was the work to help healthcare professionals at multiple levels make sense of the data and by encouraging formative feedback on the data and possible QI solutions.

To sustain momentum towards collaborative relations between multidisciplinary professional groups and move forward with NSQIP informed QI efforts, several caveats surfaced. Physician engagement with QI decisions was key for an OR Manager (\#652) reflecting on the potential for vulnerability among nurses if changes are "coming from nursing to physicians'-adding it is 'easier amongst the physician groups if they can kind of help push each other forwards'. In cases where physicians lacked trust in data validity, they would request more data and question the 'sample size'-delaying QI decisions. This caused frustration among NSQIP team members. Another key element to support and sustain QI efforts was having enough time-especially among physician champions-to review data and human resources to carry out QI initiatives.

Reflecting on their work to implement NSQIP, several participantshighlighted what they thoughtwere keyelements to consider when planning NSQIP implementation: reach

\section{Box 2 Representative quotes}

\section{How was the work done?}

Physician Champion\#120: 'I see my anesthesia champion frequently. So how frequently, well, we're in the locker room together two or three times a week...So, we have these quick hallway type meetings' Physician Champion\#922: 'Actually he and I often sit and talk when we're at work during surgeries as well'

SCR\#548: 'whether it's email, text, popping up to the 0.R between cases, they are open to meeting with me and are very responsive in that way' SCR\#548: 'allocate a work-week for an 8-day day cycle. So, the benefit in me doing that is that essentially every 7 weeks I have a week timeframe-or a week's worth of time I can dedicate to do some more of the QI work'

SCR\#642: 'We just got a person who's on modified duties. Actually, she started today. So she's going to do calls for us for a while. So that'll be nice because then we're getting her to ask a few more questions that normally we don't have time for'

Director\#502: 'I was actually really impressed with it. Like you know, I left there really excited about coming back seeing some of those things you could do (Referring to a NSQIP Conference). But then you realize... how do you do something off the side of your desk when you have a zillion things on this side of your desk already? And for our site we don't have a quality person here'

PC(\#497): 'we're also gathering data for those groups that l'm not sure is as meaningful as their data that they've already been gathering. I think we can start, like I said, reconciling and pulling back what they're doing, and then looking at things that make sense for the physician groups'

Director\#471: 'There's lots of questions about the number of cases we look at. Quality isn't about auditing every chart and that's always a difficult thing for physicians to understand... even our nursing teams don't have a good understanding about quality improvement and the processes...So we're always going back to validate the data'... 'What was your sampling size? That's not a really good sampling size. Go back and get some more...And so we've worked really hard but we still struggle that we tend to have data analysis paralysis ... our physician teams will strip that data 25 different ways, and it's like could you just help us understand what you're really looking for because we need to move forward' Director\#410: 'We had two ENT surgeries that kind of skewed the results a little bit with the SSI. Which is kind of rare for ENT, so like that's the kind of thing that you wouldn't want to send back to ENT and say-you've got a problem with your infection, right? It's kind of like, let's look at it'

Physician Champion\#497: I just stress the objectivity of it. I just say, these are the numbers, these are the domains that we're looking at. These are the numbers that were getting. I'm not pointing the finger at any particular individual or any particular group of individuals or any particular practice. But the numbers are the numbers and this is what it shows... And then this-I've immediately then followed that up withthe whole point of collecting this, is so that we, global we, institution, can get better at what we do'

Physician Champion\#937: 'I had some flexibility in order to do the job. So in my clinical, I had a bit of room in my clinical practice that wasn't filled. . if someone was doing a full clinical practice it would be difficult to fit it in' Physician Champion\#293: 'Well, the successes are, you know we have an SCR who is very dedicated and is pushing a lot of this stuff, frankly because I really have very little time in my week. So I'm glad that she is doing a lot of the legwork for me'

Director\#163: 'I think we've only had one semi-annual report, and she presented it at the surgical services meeting. So, the physicians get presented with that information. The surgeons first, and then she shares

Continued 


\section{Box 2 Continued}

it with the OR team. So, she goes to the operational kind of nursing kind of team, and shares it with them, and then we start talking, probably when we kind of determine what are the things that we want to work on, as a group. And then we start talking to other departments around what some of the data is telling us... So, she shares those reports at the quality council, once the surgeons have been given that information'

\section{How is the work sustained?}

Director\#163: 'I would say that report and what has been shared with just the NSQIP kind of, has shifted conversations to be more quality improvement focused at our site. Which I think is phenomenal. Rather than kind of, oh historically, I think we focused, this OR has focused on conflict, on problems rather not solutions to some of these challenges that we were actually seeing'

OR Manager\#652: 'I think historically, anything brought forward by nursing, there's some difficult uptake sometimes from physicians when it's coming from nursing to physicians and it always is easier amongst the physician groups if they can kind of help push each other forwards' OR Manager\#652: 'I would say that because we have physician champions which are also the chiefs of surgery and anaesthesia, I feel like it's a very collaborative approach right now, rather than kind of fighting other disciplines. We're working together and we often review... This is what anesthesia is doing. And sometimes he's even said We've identified this. Have you thought about this as far as nursing?

out to established NSQIP sites to understand processes and human/structural resources needed to get started; consider where the SCR role fits within the QI structure; provide sufficient time for physician champions to do NSQIP work; establish provincial or local SCR and Physician Champion communities of support; engage with physician and nursing groups early on to create awareness and build collaborative relationships and start with a few well supported QI changes based on the data. Additional representative quotes are highlighted in box 2 .

\section{DISCUSSION}

Integrating CFIR with NPT illuminated how implementation work in different contexts was done to embed NSQIP and support QI initiatives. Insights from our findings revealed three key elements to support and sustain NSQIP implementation: (1) provide time, space and resources for implementation teams to operationalise relationships and processes to integrate NSQIP into existing workflows; (2) use formative approaches to help others make sense of and value using NSQIP data for practice improvement and (3) engage different healthcare professionals and leadership to cocreate QI initiatives informed by NSQIP data.

Having time, dedicated funding for human resources, equipment and creating safe spaces for conversations about NSQIP was integral to the work of the implementation teams. Such resources are described as key for implementation in CFIR; ${ }^{13}$ our study illustrates how they enabled team members' participation as they individually and collectively made sense of NSQIP and their roles, understood the work to help others embrace NSQIP and identified resource capacities to support QI initiatives. Key was the support provided by the Provincial SCR and Provincial Physician Champion monthly conferences with the Provincial NSQIP Lead to do this work. Similar to experiences in a prior NSQIP study, collaborative groups provided vital support and established a community of practice to exchange ideas and learn from one another. ${ }^{12}$

Understanding and addressing any negative perceptions to NSQIP at the surgical facility level was ongoing. Prior studies identify physician resistance to NSQIP as an obstacle to uptake. ${ }^{10-12}$ Resistance among physician groups in this study related to mistrust concerning validity and use of data. Our findings add to the literature by revealing how implementation teams can bring physicians and other healthcare professionals to the table to value and engage with the data. To avoid reinforcing a negative culture for change the teams focused on what was occurring in the data and why it was happening rather than 'who' was to blame. Focusing on the what and why in the data, using deliberate language to shift attitudes from my data to our data and encouraging input from different groups at multiple levels to cocreate QI solutions-fostered a learning culture ${ }^{19}$ with a sense of agency.

Maintaining a sense of agency through a grassroots approach to encourage feedback from multiple professional and leadership groups appeared to increase collaborations. Unlike top-down approaches to quality, which often are regarded as threats to professional autonomy among physicians,${ }^{20}$ the grassroots approach drove quality changes while acknowledging expertise and autonomy among those making the changes.

\section{Limitations}

Despite recruiting participants with a broad variety of professional roles and perspectives on NSQIP, we were unsuccessful in recruiting surgeons outside of the implementation teams who were not enthusiastic about NSQIP. Although several study participants voiced understandings of why some surgeons were initially not welcoming the programme, it would be beneficial in future studies to gain insights directly from these surgeons. Demanding work schedules of participants limited our opportunity to one interview per participant. This study captured experiences approximately 1 year out from the start of implementation at these hospitals. Future work should consider long-term processes to support sustainability.

\section{CONCLUSION AND RELEVANCE}

This qualitative study is the first to provide an in-depth analysis of the work of surgical implementation team members implementing NSQIP. Our study provides new insights into cognitive and teamworking processes necessary for implementing and sustaining the NSQIP. Applying NPT and CFIR as a lens to guide this study illuminated how implementation processes and contextual factors interact and shape each other. This work provides insights into the work of implementation teams to develop shared understandings of 
work processes and reorganise themselves to work together. Our analysis also illuminates strategies the teams used to understand and overcome context-specific time/resource constraints and concerns raised within the surgical community. Overall, the work to implement and sustain NSQIP engaged most team members positively in the QI process, facilitating a shift towards increased data-focused surgical team interactions.

\section{Author affiliations}

${ }^{1}$ Physician Learning Program, University of Alberta Faculty of Medicine and Dentistry, Edmonton, Alberta, Canada

${ }^{2}$ Surgery Strategic Clinical Network, Alberta Health Services, Edmonton, Alberta, Canada

${ }^{3}$ Bone \& Joint Health Strategic Clinical Network, Alberta Health Services, Edmonton, Alberta, Canada

${ }^{4}$ Office of Lifelong Learning \& Physician Learning Program, University of Alberta Faculty of Medicine and Dentistry, Edmonton, Alberta, Canada

${ }^{5}$ Family Medicine, University of Alberta, Edmonton, Alberta, Canada

${ }^{6}$ Departments of Surgery \& Community Health Sciences, University of Calgary Cumming School of Medicine, Calgary, Alberta, Canada

Acknowledgements The authors wish to thank David Chakravorty at Alberta Health Services for helping DS to connect with the surgical implementation teams and for providing guidance to DS to deepen her understanding of NSQIP. The authors also wish to thank Indra Budiyanto at the Physician Learning Program for his outstanding graphic design work on the coding manual and Melanie Heatherington's assistance and expertise with the submission of this manuscript. Finally, the authors wish to thank all of the peer reviewers for their thoughtful and constructive feedback to strengthen the manuscript.

Contributors DC-S is the principal investigator. DC-S, TL, DS, SB, MB and JR conceived of and designed the study. DS and DC-S had full access to all of the data in the study and take responsibility for the integrity of the data and the accuracy of the data analysis. DS recruited participants and collected data. DS, TL and DC-S analysed the data and the analysis was supported by MB, SB and JR. DS, DC-S and TL drafted the manuscript. DS, DC-S, TL, SB, MB and JR revised the manuscript for important intellectual content. A presentation of the findings was provided at the Virtual American College of Surgeons' Quality and Safety Conference in August 2020.

Funding Supported by a financial contribution from Alberta Health Services and the Government of Alberta via the Physician Learning Program. The views expressed here do not necessarily represent the official policy of the Government of Alberta. There are no grant award numbers for either grants.

Competing interests None declared.

Patient consent for publication Not required.

Ethics approval This study was approved by the Health Research Ethics Board of the University of Alberta \#Pro00088327 and received operations approval from Alberta Health Services.

Provenance and peer review Not commissioned; externally peer reviewed.

Data availability statement Data are available upon reasonable request. Deidentified participant transcript data are available upon reasonable request from Dr. Denise Campbell-Scherer (denise.campbell-scherer@ualberta.ca) under the condition that sharing of data is in the form of a collaboration.

Supplemental material This content has been supplied by the author(s). It has not been vetted by BMJ Publishing Group Limited (BMJ) and may not have been peer-reviewed. Any opinions or recommendations discussed are solely those of the author(s) and are not endorsed by BMJ. BMJ disclaims all liability and responsibility arising from any reliance placed on the content. Where the content includes any translated material, BMJ does not warrant the accuracy and reliability of the translations (including but not limited to local regulations, clinical guidelines, terminology, drug names and drug dosages), and is not responsible for any error and/or omissions arising from translation and adaptation or otherwise.
Open access This is an open access article distributed in accordance with the Creative Commons Attribution Non Commercial (CC BY-NC 4.0) license, which permits others to distribute, remix, adapt, build upon this work non-commercially, and license their derivative works on different terms, provided the original work is properly cited, appropriate credit is given, any changes made indicated, and the use is non-commercial. See: http://creativecommons.org/licenses/by-nc/4.0/.

ORCID iD

Denise Campbell-Scherer http://orcid.org/0000-0002-2500-8207

\section{REFERENCES}

1 Cohen ME, Liu Y, Ko CY, et al. Improved surgical outcomes for ACS NSQIP hospitals over time: evaluation of hospital cohorts with up to 8 years of participation. Ann Surg 2016;263:267-73.

2 Guillamondegui OD, Gunter OL, Hines L, et al. Using the National surgical quality improvement program and the Tennessee surgical quality collaborative to improve surgical outcomes. J Am Coll Surg 2012;214:709-14.

3 Hall BL, Hamilton BH, Richards K, et al. Does surgical quality improve in the American College of surgeons national surgical quality improvement program: an evaluation of all participating hospitals. Ann Surg 2009;250:363-76.

4 Khuri SF, Henderson WG, Daley J, et al. Successful implementation of the Department of Veterans Affairs' national surgical quality improvement program in the private sector: the patient safety in surgery study. Ann Surg 2008;248:329-36.

5 Rowell KS, Turrentine FE, Hutter MM, et al. Use of national surgical quality improvement program data as a catalyst for quality improvement. J Am Coll Surg 2007;204:1293-300.

6 Nimeri AA, Bautista J, Philip R. Reducing healthcare costs using ACS NSQIP-Driven quality improvement projects: a success story from Sheikh Khalifa medical City (SKMC). World J Surg 2019;43:331-8.

7 van Katwyk S, Thavorn K, Coyle D, et al. The return of investment of hospital-based surgical quality improvement programs in reducing surgical site infection at a Canadian tertiary-care Hospital. Infect Control Hosp Epidemiol 2019;40:125-32.

8 Thanh NX, Baron T, Litvinchuk S. An economic evaluation of the National surgical quality improvement program (NSQIP) in Alberta, Canada. Ann Surg 2019;269:866-72.

9 Hollenbeak CS, Boltz MM, Wang L, et al. Cost-effectiveness of the National surgical quality improvement program. Ann Surg 2011;254:619-24.

10 Raval MV, Bentrem DJ, Eskandari MK, et al. The role of surgical champions in the American College of Surgeons National surgical quality improvement program-a national survey. J Surg Res 2011;166:e15-25.

11 Neuman HB, Michelassi F, Turner JW, et al. Surrounded by quality metrics: what do surgeons think of ACS-NSQIP? Surgery 2009:145:27-33.

12 Velanovich V, Rubinfeld I, Patton JH, et al. Implementation of the National surgical quality improvement program: critical steps to success for surgeons and hospitals. Am J Med Qual 2009;24:474-9.

13 Damschroder LJ, Aron DC, Keith RE, et al. Fostering implementation of health services research findings into practice: a consolidated framework for advancing implementation science. Implement Sci 2009; 4:50.

14 May C, Finch T.Implementing, embedding, and integrating practices: an outline of normalization process theory. Sociology 2009;43:535-54.

15 American College of Surgeons National Surgical Quality Improvement Program. About ACS NSQIP, 2021. Available: https://www.facs.org/ quality-programs/acs-nsqip/about

16 O'Brien BC, Harris IB, Beckman TJ, et al. Standards for reporting qualitative research: a synthesis of recommendations. Acad Med 2014;89:1245-51.

17 Braun V, Clarke V. Using thematic analysis in psychology. Qual Res Psychol 2006;3:77-101.

18 Morse JM. Critical analysis of strategies for determining rigor in qualitative inquiry. Qual Health Res 2015;25:1212-22.

19 Khatri N, Brown GD, Hicks LL. From a blame culture to a just culture in health care. Health Care Manage Rev 2009;34:312-22.

20 Adler PS, Kwon S-W. The mutation of professionalism as a contested diffusion process: clinical guidelines as carriers of institutional change in medicine. Journal of Management Studies 2013:50:930-62. 